\title{
CORRIGENDUM
}

\section{Assessment of endotracheal tube placement in newborn infants: a randomized controlled trial}

S van Os, P-Y Cheung, K Kushniruk, M O'Reilly, K Aziz and GM Schmölzer

Journal of Perinatology (2016) 36, 796; doi:10.1038/jp.2016.109

Correction to: Journal of Perinatology (2016) 36, 370-375; doi:10.1038/jp.2015.208

The Figure 1 panel descriptions were presented incorrectly. The correct legend appears below.
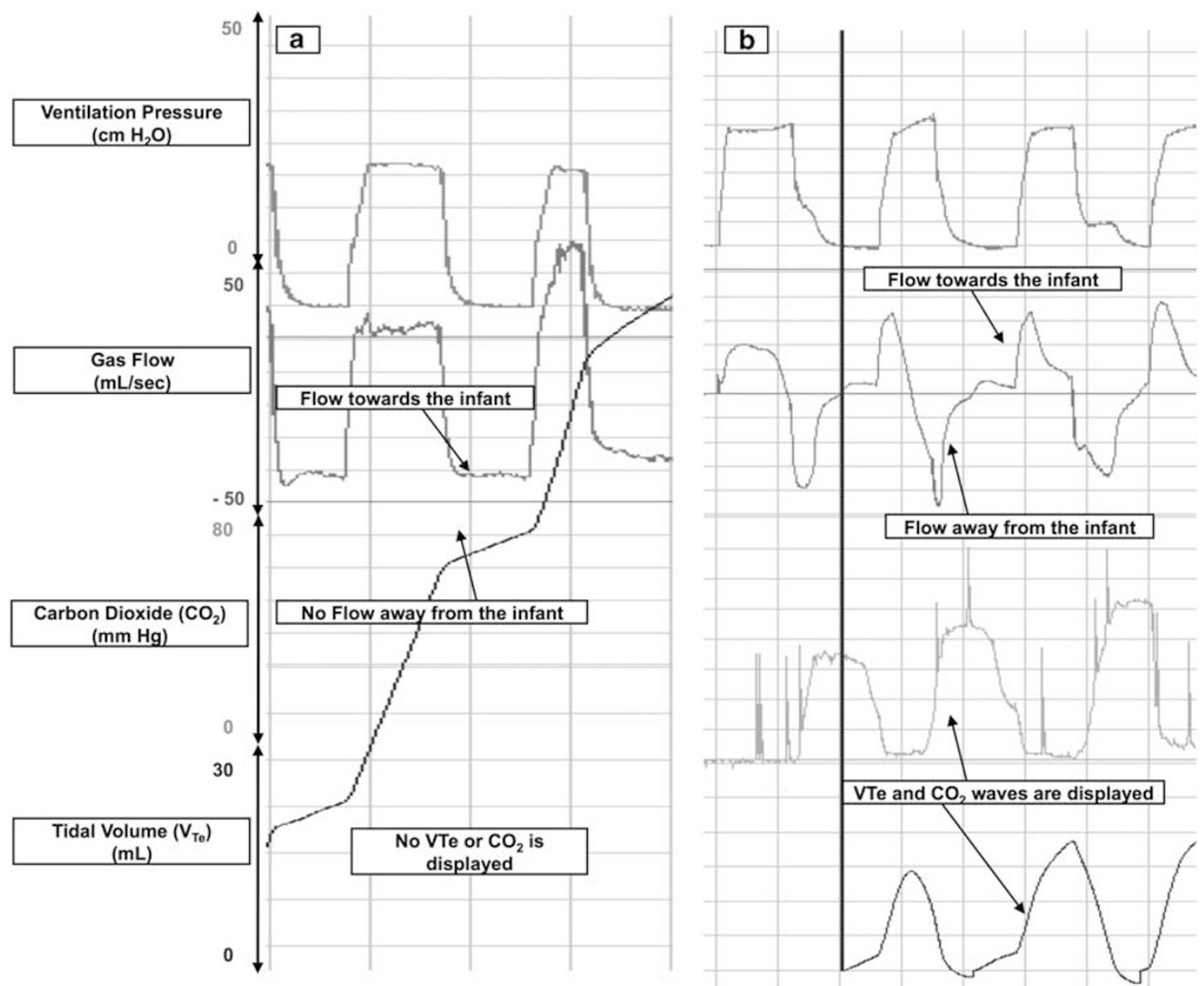

Figure 1. Flow and end-tidal $\mathrm{CO}_{2}\left(\mathrm{ETCO}_{2}\right)$ waveforms to identify esophageal (a) or endotracheal (b) tube placement. ${ }^{24}$ 